\title{
28
}

\section{The physical and mineralogical characteristics of pottery from Mochong, Rota, Mariana Islands}

\section{Foss Leach}

Honorary Research Associate, Museum of New Zealand Te Papa Tongarewa, Wellington, New Zealand Foss.Leach@University-of-Ngakuta.ac.nz

\section{Janet Davidson}

Honorary Research Associate, Museum of New Zealand Te Papa Tongarewa, Wellington, New Zealand

\section{Graeme Claridge}

33 Kotari Rd, Days Bay, Lower Hutt, New Zealand

\section{Graeme Ward}

Australian Institute of Aboriginal and Torres Island Studies, Canberra, Australia

\author{
John Craib \\ Bonhomme Craig and Associates, Mudgeeraba, Queensland, Australia
}

\section{Introduction}

In a reflective paper about the relationship between archaeometry and archaeology, Atholl observed that 'whereas most archaeological data arise from direct observation or the use of simple equipment, archaeometrical data are characteristically created by complex machinery, the use of which is sometimes taken as a rule-of-thumb guide to the limits of the subject' (Anderson 1987:3). He identified a gulf between the two disciplines which is only briefly bridged when archaeologists themselves colonise one attractive new methodological patch created by archaeometrists before moving on to the next (ibid:13). We hope that Atholl will appreciate our attempt here to occupy a new patch using bucket chemistry and only simple equipment with no flashing lights and fancy dials, in an effort to learn a little more from tiny scraps of apparently insignificant pot sherds. 
Studies of Marianas pottery have generally focused on variables such as rim form, surface treatment, temper type, and sherd thickness (e.g. Moore 1983; Sant and Lebestki 1988). A classification based on temper was already established (Reinman 1977; Leidemann 1980; Ray 1981; Moore 1983) when the present study was initiated and has since been further developed (Dickinson et al. 2001:831; Dickinson 2006:40). More recent studies have also explored clay pastes (e.g. Graves et al. 1990; Dickinson et al. 2001). Changes in vessel form have been identified (e.g. Moore and Hunter-Anderson 1999). However, it is thought that there was 'a single evolving Mariana ceramic tradition forming a continuum that spans Pre-Latte and Latte times' (Dickinson et al. 2001:829). The present study aimed to explore physical and technological aspects of Marianas pottery through water-absorption tests, differential thermal analysis, and mineralogical description.

In 1983, Ward and Craib (1983) carried out excavations at Mochong on the northeast coast of the island of Rota (Figure 1). The excavation consisted of a series of squares (TP1-TP8) on a $150 \mathrm{~m}$ long transect. TP8, from which the analysed pottery samples were taken, was on the inland side of a latte structure (ML13) in a part of the site in which relatively early deposits were known to exist. It was also the least disturbed part of the site. Five radiocarbon dates from TP8 range from 540 to 2450 years BP (Leach et al. 1988:47). Pottery was common in the excavations.

At Mochong, there was a clear stratigraphic separation of the earlier CST (calcareous sand tempered) and later VST (volcanic sand tempered) sherds. However, pottery identified as MST (mixed sand tempered) occurred at several levels in the excavation. It was decided to select samples from two chronological periods to see whether any significant change in pottery technology could be detected. Details of the samples analysed are given in Table 1. In each case, 25 sherds were selected for analysis. These were grab samples, subjectively chosen as representing the range of pottery available in each category.

Stratum IIa, from which Assemblages A and C derive, is associated with the latte feature ML13 and has a radiocarbon date of 540 460 (Beta-9651), confirming the latte association.

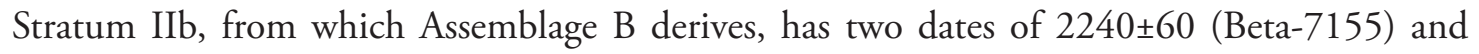
$2110 \pm 80$ (Beta-9652), placing this material firmly in the Intermediate Pre-Latte Period, which is now thought to date between 2500 and 1600 BP (Moore and Hunter-Anderson 1999). Assemblage $\mathrm{D}$ derives from the underlying Stratum IV, which is undated but bracketed between the two previous dates and a basal date of $2450 \pm 90$ (Beta-9653). Assemblage D probably also dates to the Intermediate Pre-Latte Period. Takayama and Intoh (1976:21) obtained a date of

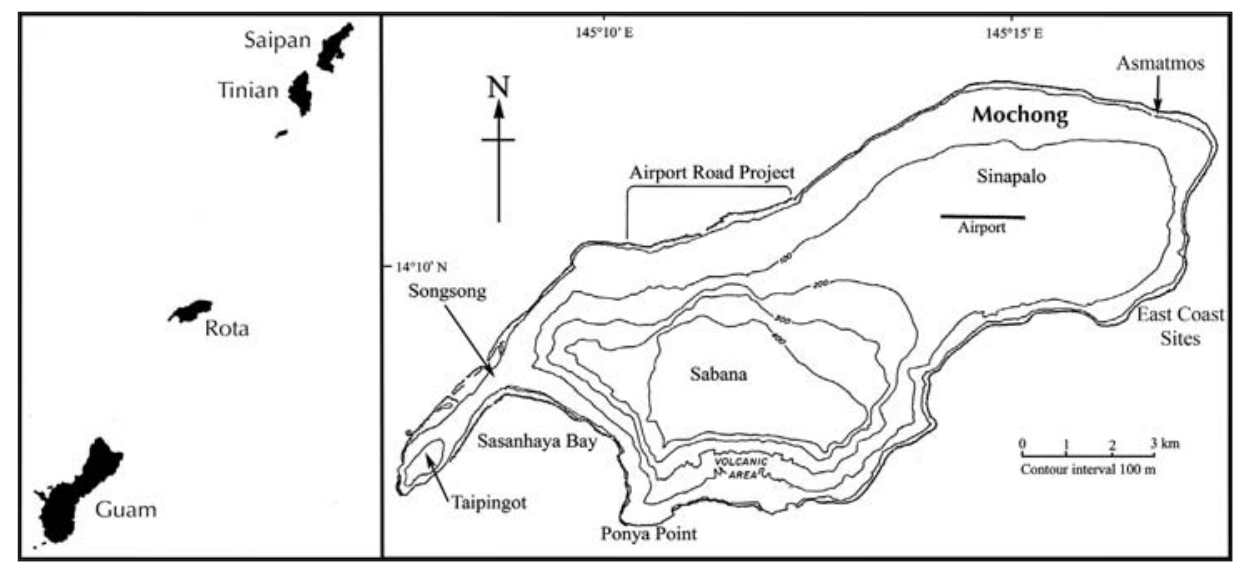

Figure 1. The island of Rota in the Mariana Islands showing the location of the Mochong site. Dickinson et al. (2001) sampled sherds from Mochong, Asmatmos and five east coast sites. 
Table 1. Pottery samples analysed from TP8 at Mochong.

\begin{tabular}{lllll}
\hline Assemblage & Stratum & Spits & Temper type & Period \\
\hline A & Ila & 3 and 4 & MST & Latte \\
B & Ilb & 7 and 8 & MST & IPL \\
C & Ila & 3 and 4 & VST & Latte \\
D & IV & 9,10 and 11 & CST & IPL \\
\hline
\end{tabular}

IPL = Intermediate Pre-Latte Period.

$2590 \pm 85 \mathrm{BP}$ for a layer near the base of their earlier excavation in the Mochong site, and some Early Pre-Latte material was recovered in their excavations.

\section{Physical characteristics}

Water-absorption tests were carried out using the method described by Intoh (1982). These tests reveal physical characteristics of pottery, and are very helpful in discerning similarities and differences in the pottery technology of different prehistoric groups. Special standard tiles were used to check on reproducibility of results. The basic results of these tests are given in Appendix 1, which lists the percentage water absorption (WA), apparent porosity (AP), bulk density (BD), and specific gravity (SG) for each sherd. For each assemblage, summary statistics are given, including the mean and its associated standard error, the standard deviation and its standard error, the skewness and kurtosis statistics (G1 and G2, see Geary and Pearson 1938; Geary 1947), and the associated normalised deviates (W1 and W2, see Rao 1952:219).

The clearest differences revealed by these analyses concern the CST and VST pottery types. For example, the mean porosity is considerably higher in the case of CST pottery ( 45.3 percent cf. 37.0 percent, $t=5.4$ with 42 degrees of freedom, which is significant $\mathrm{p}=.001$ ). Similar, but less marked, differences are found in the case of bulk density and specific gravity. The CST pottery has a lower bulk density and a higher specific gravity. Another interesting feature is that there is significant negative skewness in the case of VST apparent porosity. This is largely due to three very low values for sherds AT606, AT607 and AT613. The remainder of the VST values form a fairly tight distribution about the mean figure. This may indicate that included in the VST pottery assemblage are some unusual sherds, perhaps from a different source than the majority of sherds in this assemblage. In this analysis, the two MST assemblages are similar to each other and to the VST pottery.

In Figure 2, the positions of a wide range of prehistoric pottery assemblages from the Pacific are plotted, using the mean figures for apparent porosity and specific gravity. The original study on which this information is based was carried out by Intoh (1982). There are several interesting features in Figure 2. It will be noticed, for example, that the Mochong MST and VST pottery has an unusually low specific gravity, making it rather distinct from other Pacific Island traditions. The Mochong calcareous pottery, on the other hand, plots out quite close to Palau plain ware (\#15), Fefan Island calcareous ware (\#22), and the two Marianas samples studied by Intoh, characterised as Marianas plain ware (\#18) and Marianas red ware (\#19). The only other calcareous pottery available for comparison was from the Yap Islands (\#17). This has a similarly high apparent porosity, but significantly higher specific gravity.

\section{Thin-section characteristics}

Thin sections were prepared at Otago University and were examined with optical microscopy by Claridge and Mr A.V. Weatherhead. Mineral grain and calcite contents were estimated by 


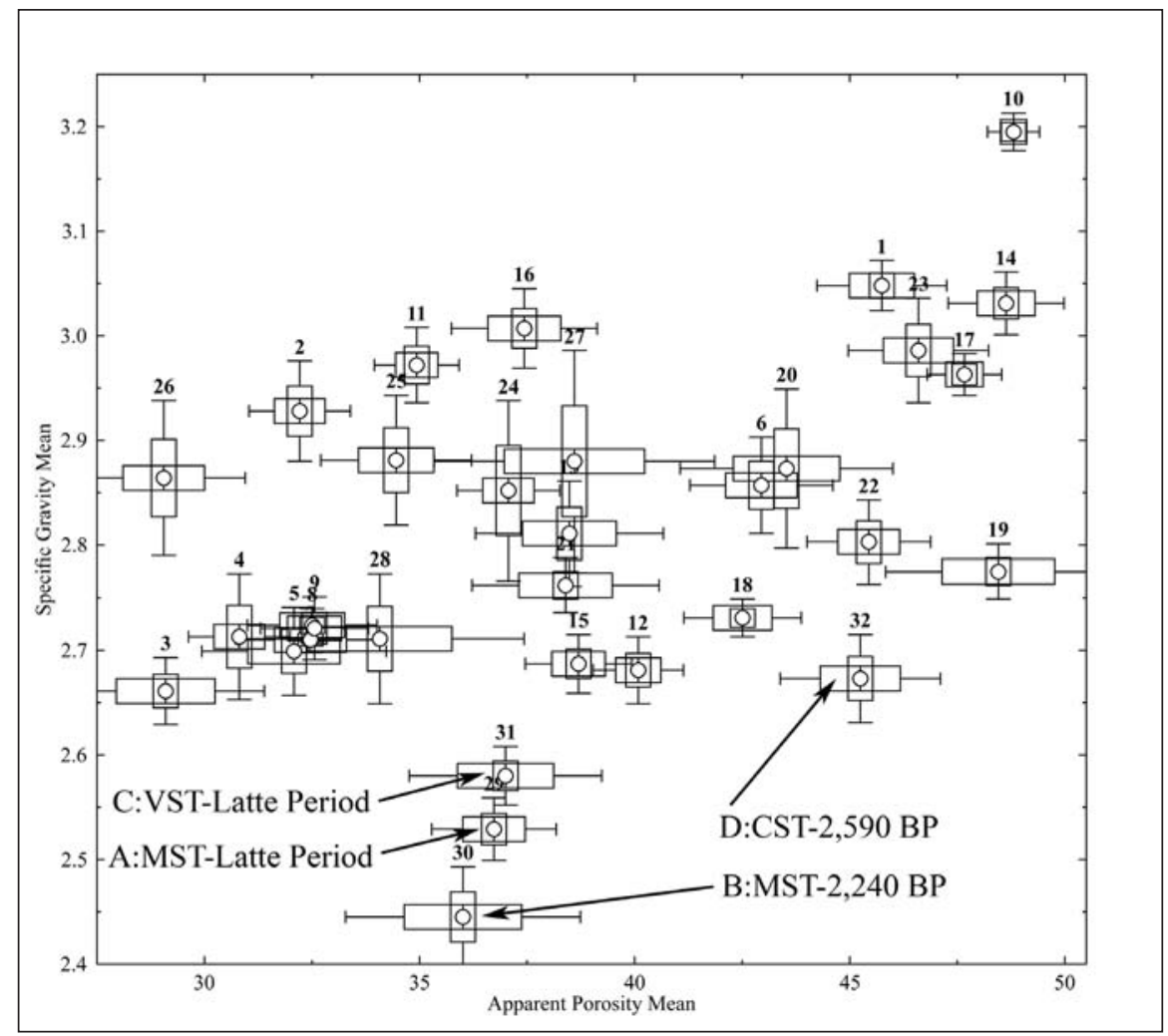

Figure 2. Physical characteristics of Pacific Island prehistoric pottery.

1=Reef Islands Lapita, $2=$ Vailele thick coarse ware, $3=$ Yanuca early-Lapita decorated ware, $4=$ Yanuca early plain ware, $5=$ Yanuca late plain ware, $6=$ Yap late laminated ware, $7=$ Yanuca middle-period paddle-impressed (parallel-rib), $8=$ Yanuca middle-period paddle-impressed (cross-hatch), $9=$ Yanuca middle-period plain ware, $10=$ Sasoa ${ }^{2}$ thin fine ware, $11=$ Sasoa a thick coarse ware, $12=$ Taumako andesitic ware, 13=Taumako pyroxenic ware, 14=Yap middle-period unlaminated ware, 15=Palau plain ware, 16=Mulifanua Lapita ware, 17=Yap early calcareous ware, 18=Marianas plain ware, 19=Marianas red ware, $20=$ Ngulu Island ware, $21=$ Banks Islands ware, $22=$ Fefan Island calcareous ware, 23=Nan Madol plain ware, 24=Lakeba Lapita ware, 25=Natunuku Lapita ware, 26=Natunuku paddle-impressed ware and late incised, $27=$ Sigatoka paddle-impressed ware, $28=$ Lakeba paddleimpressed ware and late plain, 29=Mochong Assemblage A MST, 30=Mochong Assemblage B MST, 31=Mochong Assemblage C VST, 32=Mochong Assemblage D CST.

comparison with reference charts and are quoted on an area basis. Mineral species were identified by their optical properties, confirmed in one case by separation of the heavy mineral fraction from crushed material and X-ray diffraction analysis. The composition of the mineral fraction was estimated visually. The colour of the section was determined from the appearance of the slide in the microscope, viewed in reflected light. Colours are Munsell colour notation. The detailed descriptions are given in Appendix 2.

The cracking parallel to the axis of the sherds, evident on most of the sections, is probably due to shrinkage of the clay matrix during drying before firing. In some cases the cracks were clearly infilled with mounting medium and were present before sectioning, while in others they may have been produced during preparation of the section, as infillings were not obviously present. This question could probably be resolved by SEM observation of broken faces of the sherds. Cracking perpendicular to the axis or random cracking may be a result of deterioration of the sherd by weathering. 
Mineral content varies widely, but in general, appears low. The composition of the mineral fraction also varies. In some cases, quartz is dominant; in others, feldspar or ferromagnesians are dominant. It was concluded that the non-calcareous sand-size grains were present in the original clay, and were not added deliberately. Where calcite is present, this has been added in considerable amounts and the addition must have been deliberate. The sand appears to be a fine-grained beach deposit formed from coral and marine shells.

The mineral content is consistent with a clay formed from strongly weathered soils from andesitic parent materials, which have been transported as alluvium or colluvium, as the sand grains are in many cases sharp and angular. However, the variation in composition of the mineral fraction points to different sources for the clay. These differences may correspond to those in deliberately added temper sands identified by Dickinson et al. (2001), who have shown that significant quartz content is typical of temper originating on Saipan, while olivine and high ferromagnesian content is typical of temper originating on Guam. However, they report restricted exposures of andesitic rock on Rota (ibid: 834, 836), and Dickinson (2006:42) reports some temper so far unique in the Marianas in sherds he studied from Mochong. It seems likely that at least some of the pottery found at Mochong was made locally.

The multi-coloured aspect of the Mochong sherds is due partly to mixing of clays during preparation of the body, partly to differential weathering, and partly to variation in penetration of the firing heat into the clay. Many of the sherds show a red colour on the outside and a darker colour inside, as if temperatures on the inside of the fired article did not rise sufficiently high to burn out the organic constituents of the clay. However, such an effect can also be the result of a small soak time, typical of flash firing at low temperature, with a reducing atmosphere inside the pot.

In other cases, the sections show the presence of reddish globules, which appear to be iron-rich clay, produced by weathering of ferromagnesian minerals. This may be important in considering whether the absence of ferromagnesians is significant in assessing the origin of the clay.

Evidence of low firing temperature in some sherds is the presence of birefringence in the matrix arising from preferred orientation of clay particles. Its presence in these thin sections indicates that the clay structure is still largely present and therefore that firing temperatures did not rise sufficiently high for the structure to be destroyed. This can be expected to begin between 500 and 600C. Some birefringence is present in a Latte Period sherd (AT624) as well as in an early CST tempered sherd (AT633) (see Appendix 2).

There are some interesting differences between the assemblages, notably between the two MST assemblages. The sherds examined from Assemblage A contained no calcite, whereas those from Assemblage B all contained significant amounts. In this analysis, Assemblage A (MST) looks very like Assemblage C (VST). Assemblage B (MST) looks like Assemblage D (CST). There is also at least one difference in mineral content that may be significant. The mineral content of all the sherds from Assemblage B is high in quartz (estimated at 90 percent in all five sherds), whereas quartz is low in Assemblage A (averaging 12.5 percent). The quartz content is variable in the other two assemblages.

These characteristics are summarised in Table 2. The high quartz content of all analysed sherds in Assemblage B is similar to that of some sherds of CQT (quartz-calcite) temper from predominantly Pre-Latte contexts, including one from Rota, in the study of Dickinson $e t$ al. (2001:843, Table VI). Dickinson et al. state that Saipan origin can be confidently inferred for any sherd with quartz content higher than 1-2 percent. This would indicate that almost all of the Mochong sherds studied originated on Saipan. However, the presence in at least one 
Table 2. Mineral and calcite content of Mochong sherds examined in thin section, and amount of quartz in mineral content.

\begin{tabular}{|c|c|c|c|c|}
\hline Assemblage & Sherd & Mineral(\%) & Calcite(\%) & Quartz \\
\hline AMST & AT554 & 20 & - & low \\
\hline AMST & AT556 & $1-2$ & - & low \\
\hline AMST & AT557 & 5 & - & low \\
\hline AMST & AT559 & 2 & - & low \\
\hline B MST & AT581 & 10 & 10 & high \\
\hline B MST & AT583 & 1 & 20 & high \\
\hline B MST & AT584 & 10 & 30 & high \\
\hline B MST & AT598 & 5 & 40 & high \\
\hline B MST & AT602 & 15 & 15 & high \\
\hline CVST & AT605 & 10 & - & low \\
\hline CVST & AT619 & 15 & - & low \\
\hline CVST & AT620 & 5 & - & medium \\
\hline CVST & AT623 & 10 & $5-10$ & high \\
\hline CVST & AT624 & 5 & - & low \\
\hline DCST & AT628 & $>1$ & 50 & high \\
\hline DCST & AT629 & 5 & 5 & low \\
\hline DCST & AT630 & 2 & 20 & medium \\
\hline DCST & AT633 & 5 & 30 & medium \\
\hline DCST & AT643 & 5 & 20 & high \\
\hline
\end{tabular}

High $=80 \%$ or more, medium $=40-50 \%$, low $=25 \%$ or less.

Mochong sherd (AT629) of both quartz and olivine (the latter identified by Dickinson $e$ al. as typical of Guam rather than Saipan tempers) indicates the picture is probably more complex.

\section{Differential thermal analysis}

Differential thermal analysis (DTA) is a valuable tool for estimating the maximum firing temperature a pot has reached. A powdered sample of the pottery is used, along with a control sample of inert material. Both are placed in an aluminium block and heated at a controlled rate in an electric furnace. A differential thermocouple is used to measure the temperature difference between the pottery and the control, and this is plotted against the pottery temperature during refiring. If the pottery temperature is higher than the control at any point, this is due to exothermic reactions taking place inside the pottery. If it is lower, this is due to endothermic reactions taking place (Tite 1972:295ff.).

The presence of an endothermic peak for a known mineral in the pottery indicates that the pot has never been fired to this temperature before. Conversely, the absence of such a peak indicates that the pot has been fired to at least this temperature previously. Some well-known peaks are as follows:

1. 100-200C: a broad endothermic peak in this range is due to the loss of absorbed water in the sample. This peak should be present in virtually all samples. 
2. 250-500C: a broad exothermic peak in this range is due to the combustion of organic material in the pottery. Its presence depends on the amount of organic material in the pottery.

3. 550-600C: an endothermic peak here indicates the loss of chemically combined hydroxyl water by clay minerals such as kaolin. When this peak is present, it shows the pottery has not been heated above this temperature previously; when it is absent, the pottery has been fired above this temperature.

4. 800-900C: an endothermic peak here indicates the decomposition of calcite. When this peak is present, it shows the pottery has not been heated above this temperature previously; when is it absent, the pottery has been fired above this temperature.

5. 900-1000C: an exothermic peak in this range is due to the formation of various hightemperature mineral phases from clay. When this peak is present, it shows the pottery has not been heated above this temperature previously. When this peak is absent, there can be several reasons: (i) the pottery had not previously been fired above this temperature; (ii) a large endothermic calcite peak is concealing the smaller exothermic peak; (iii) kaolin was not present in the original pottery paste.

Five samples from each assemblage were examined by DTA; the curves of each of these samples are shown in Figures 3 and 4.

The sherds in Figure 3 are from early contexts in the Mochong site, dating to about 2200 years BP and earlier. Both the earliest CST type and the stratigraphically slightly later MST type have strong endothermic peaks between 800 and 900C, showing that calcite had not been fired to this temperature previously. The lack of significant endothermic peaks at 550-600C suggests that clay minerals had previously been dehydroxylated by being fired above this temperature. Sherd AT629 shows a small peak at 550C, attributable to kaolin. This pot must have been fired at a temperature either close to or not exceeding this value. It is interesting that this pot has very little calcite in it (c. 5 percent, see Table 2) and this is reflected in an equally small calcite endothermic peak. Sherd AT581 shows a very strong exothermic peak due to organic matter in the pottery. It also has a fairly low abundance of calcite (c. 10 percent), once again reflected in the lack of a pronounced calcite peak. It is concluded that both the CST and MST pottery, dating to at and before about 2200 years BP, were fired above 550-600C and below 800-900C; that is, between 600 and $800 \mathrm{C}$. The presence of the small peak at $550 \mathrm{C}$ on one of the pots suggests the firing temperatures were probably closer to the bottom end of this range, perhaps 650-700C.

The DTA curves for the later MST and VST pottery samples (Figure 4), dating to the Latte period, are very different from the earlier ones, and quite similar to each other. They are relatively featureless, suggesting higher original firing temperatures than in the earlier pottery. There are signs of organic material in most of the curves. None of the curves show endothermic peaks around 550-600C, suggesting that clay minerals had previously been dehydroxylated by firing above this temperature. Only AT623 possessed calcite in thin section (Table 2), yet the DTA curve shows no sign of the 800-900C endothermic peak associated with the decomposition of calcite. Therefore, this sherd would have been fired above this temperature. Unfortunately, none of the other sherds contained enough calcite to prove that this firing temperature applied to them as well. However, clearly the technology did exist to fire at or above this temperature, so it is a reasonable inference that other pots were fired at least this high too. Further evidence for this is provided by only small indications of the exothermic peak between 900-1000C 


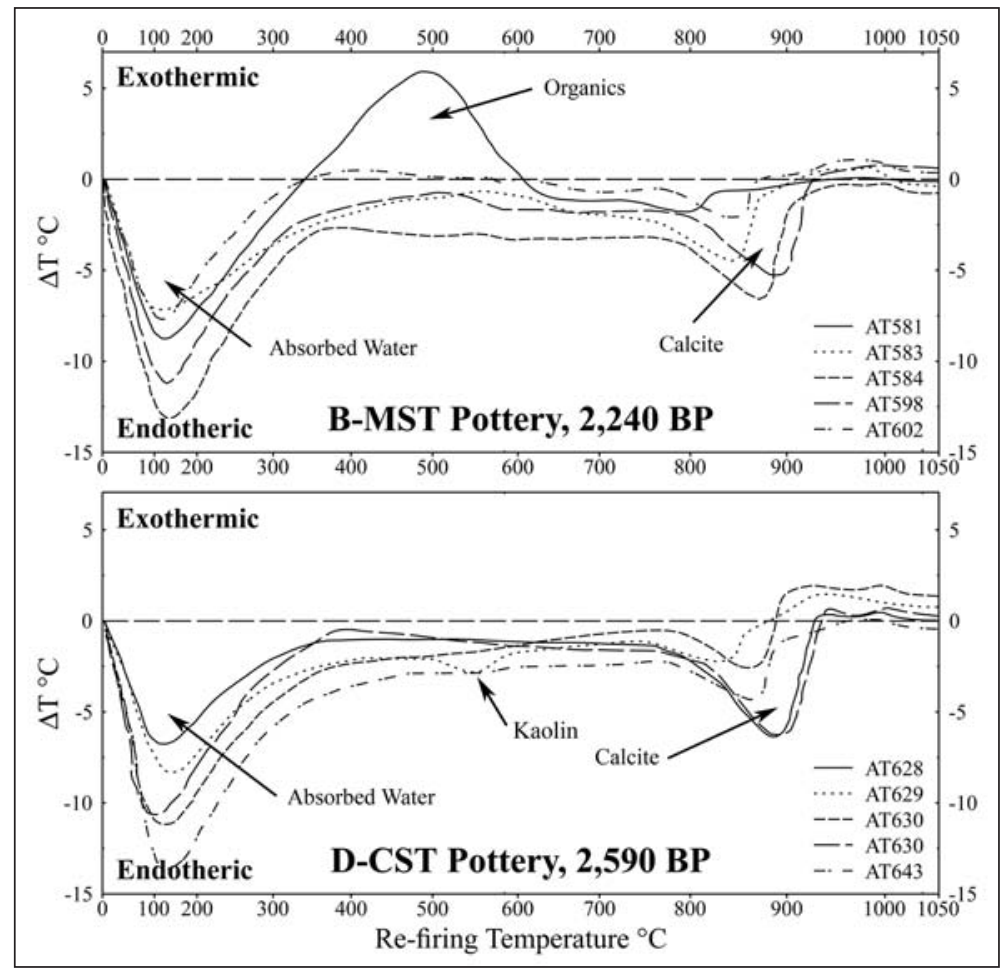

Figure 3. Differential thermal analysis of the two early assemblages of pottery from Mochong. A firing temperature of $650-700 \mathrm{C}$ is indicated.

associated with formation of clay minerals such as mullite. The absence of an endothermic peak at $800-900 \mathrm{C}$ and the diminutive exothermic peak at $900-1000 \mathrm{C}$ suggest an original firing temperature between these two values, about 900C, for these two Latte-period pottery types.

\section{Discussion}

Pottery is a common artefact in the Mariana Islands, and has been studied and classified by many previous workers. Spoehr (1957:108-122), on the basis of his investigations in Saipan, Tinian and Rota, defined two main types, Marianas Plain and Marianas Red. Marianas Plain and related decorated wares were associated with the Latte phase of Marianas prehistory, and Marianas Red with the earlier, Pre-Latte phase. Subsequent workers have had difficulty with the category of Marianas Red, particularly, although Spoehr's two basic chronological divisions pottery associated with the Latte and Pre-Latte phases - have continued to be used and further defined.

Ray (1981) and Reinman (1977), studying pottery from Guam, a short distance south of Rota, independently recognised the significance of temper as a criterion for classifying pottery from the Marianas. Reinman (1977:62-66) analysed sherds from excavations at five sites in southern Guam and established the categories of CST and VST pottery for the Pre-Latte and Latte-phase pottery respectively. He recognised that his CST pottery contained mixed tempers as well as purely calcareous temper.

Leidemann (1980) used Reinman's classification in her study of spatial and temporal variation at Ypao Beach on Guam, but established a separate category, MST, for the mixed temper which Reinman had included in his CST category.

Ray recovered nearly 5000 sherds of pre-Latte pottery from two adjacent excavations at Tarague Beach in northern Guam, as well as a quantity of later pottery. He called the earlier 


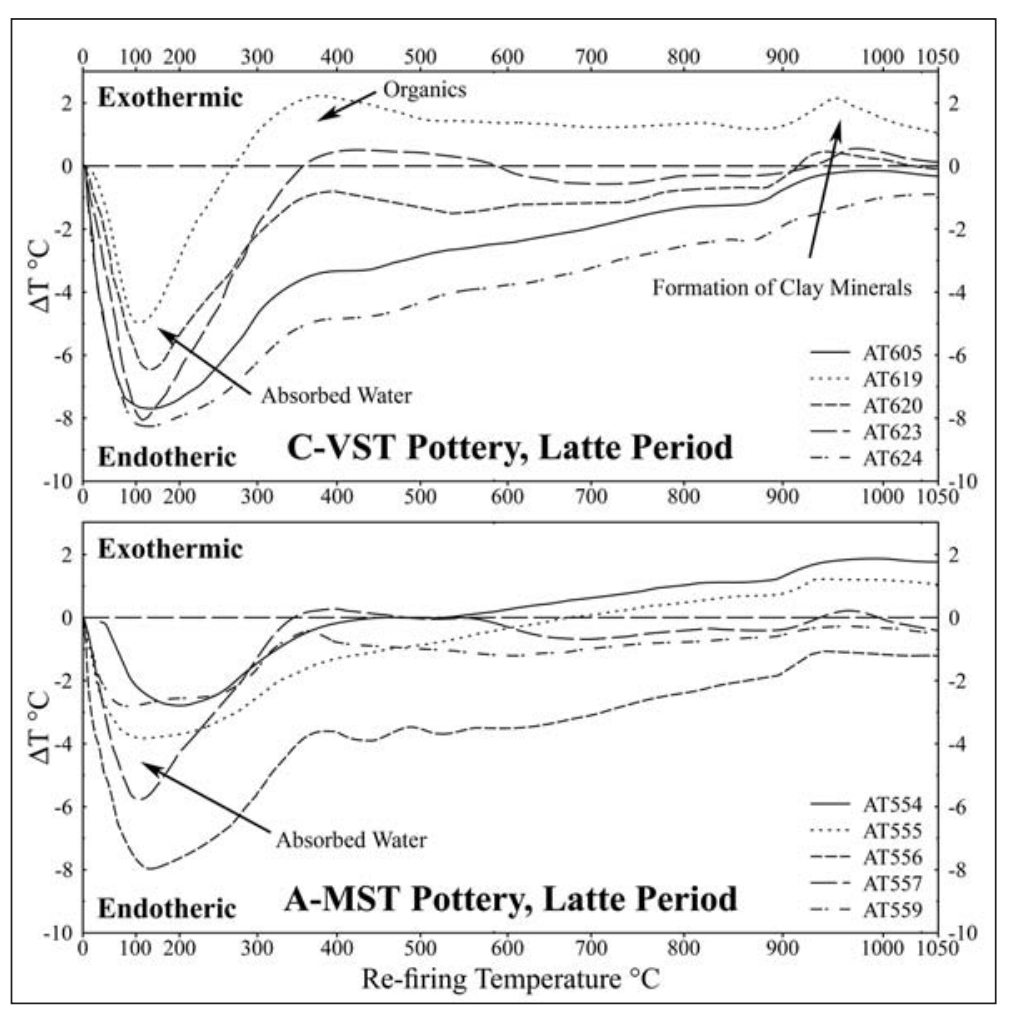

Figure 4. Differential thermal analysis of the two Latte-period assemblages from Mochong. A firing temperature of $900 \mathrm{C}$ is indicated.

pottery Mariana Red (not the same as Spoehr's Marianas Red) and defined it in some detail (Ray 1981:111-112). In this early pottery, he identified seven temper types (one having two variants), which he subsequently placed into four groups, calcareous sand (CST), volcanic sand (VST), mixed sand (MST) and rare or exotic (no acronym) (ibid:80-83, 115-122). One of his rare temper types consisted of 70 percent to 100 percent crystalline quartz. Ray demonstrated a decline in CST sherds and an increase in MST sherds in the four strata at Tarague from which he recovered his early pottery. He also proposed a possible trend from an early use of 'fat' or pure clay, to later use of clay with more natural inclusions, perhaps because the earlier sources had been depleted (ibid:79, 143). In his later Marianas Plain pottery, VST sherds comprised 15 percent, but MST, CST and exotic sherds each represented only 1 percent or less. Other temper types identified were crushed rock, 'trashy' appearing, and sparse, but Ray found the distinctions less clear cut than in the earlier pottery (ibid:143-145).

Further excavations were carried out at Tarague in 1980 (Kurashina and Clayshulte 1983) and the pottery was studied in detail by Moore (1983). She also recognised the significance of temper, but found that it was a 'temporally ambiguous attribute for determining fine temporal intervals' (ibid:172). Moore's study of temper was restricted by the facilities and resources available to her and she therefore based her analysis on the previously recognised categories of CST, VST and MST, with the addition of limonite and crushed limestone. However, she noted that clay from Mt Santa Rosa on Guam's northern plateau contained natural mineral inclusions, and that this clay, tempered with CST, would produce pottery that looked like her MST category. She also suggested that some VST pottery could have been made from untempered clay with natural mineral inclusions. The addition of CST, however, was probably deliberate (ibid:77-78).

Subsequent studies have shown that quartz is a significant component of some Mariana sand tempers. Variants of VST tempers include volcanic-quartz temper (VQT or VSQT) where 
quartz is prominent, and quartz temper (QT) where quartz is dominant. A separate category of quartz-calcite tempers (CQT, QCT or CSQT) has been established for variants of mixed sand tempers consisting of admixtures of quartz grains from volcanic bedrock and calcareous grains of reef detritus (Dickinson et al. 2001:831). As noted above, all quartz tempers are attributed to Saipan (Dickinson et al. 2001).

The results presented here add to our knowledge of pottery technology in the Mariana Islands. Firstly, the suggestion made by Moore (1983:77-78) that mineral inclusions in some of the pottery from Guam were natural rather than deliberately added is supported. At least in the Mochong pottery, the minerals do not appear to have been deliberately added, but are probably part of the original clays collected for making pottery. This is contrary to the findings of Dickinson et al. (2001:837), who found 'distinct size differences between the smallest temper grains and the largest silt grains enclosed within clay pastes'. However, they did not include any sherds from Tarague in their study (ibid:836).

It may be that in some places in the Mariana Islands, particular clays were deliberately chosen because of their mineral composition - that is, they possessed natural grit which functioned as a tempering material to minimise thermal shock during firing. A similar conclusion was arrived at for the potteries on the Yap Islands, some $740 \mathrm{~km}$ south of Guam. It was argued that in the case of the highly characteristic laminated ware from this island, the mineral content is natural (Intoh and Leach 1985:73), while in the case of the plain ware, some vessels were formed with deliberately added mineral tempering (ibid:81). As at Mochong, there is also a calcareous sand tempered ware, and these inclusions are certainly deliberate.

The sequence of change in temper type in Marianas pottery is supported at a gross level by the pottery from Mochong. Calcareous sand temper is present only in negligible amounts in later pottery associated with the Latte phase, as other workers have found (Moore 1983:87, 172). Only one of the VST sherds (AT623) from Stratum IIa that were examined in thin section contained calcite and this was low (5-10 percent). None of the sherds from Stratum IIa classified as MST and examined in thin section contained calcite.

None of the sherds studied from Mochong can be regarded as pure CST, rather than MST, since all contain some minerals. It is possible that early potters on Guam used 'purer' clay than their colleagues on Rota, and that the use of some Guam clays with CST additions produced the true CST pottery recognised by archaeologists working in Guam. The category of CST pottery from Mochong appears to contain naturally occurring minerals and deliberately added calcareous sand temper. If pottery was made at the same time on both Rota and Guam, one might expect variations in mineral content due to the use of different clay sources.

The Mochong sherds could now be classified as various kinds of quartz-tempered pottery, since all those examined in thin section contain varying amounts of quartz, ranging from five percent to 95 percent. The Latte-period Assemblages A and C (with the exception of sherd AT623) appear to be volcanic-quartz temper (variously labelled VQT or VSQT). Assemblages $\mathrm{B}$ and D have quartz-calcite tempers (CQT, QCT or CSQT). Sherd AT623 is, in this respect, closer to quartz-calcite temper.

The separate identity of MST pottery from Mochong is not clear. As indicated above, there is a definite difference between the two MST assemblages. All sherds in the earlier Assemblage B contain both calcite and minerals; however, none of the sherds from the later Assemblage A contains calcite. The classification of this assemblage as MST is therefore questionable on mineralogical grounds. In this respect, the MST (A) and VST (C) assemblages from the Latte period appear indistinguishable.

The porosity analysis reveals a difference between the assemblages containing calcite: 
Table 3. Apparent Porosity of calcareous sand tempered sherds from Mochong.

\begin{tabular}{lllll}
\hline Assemblage & Sherd & Calcite & Minerals & Apparent Porosity \\
\hline B & AT581 & $10 \%$ & $10 \%$ & $27.0 \%$ \\
B & AT583 & $20 \%$ & $1 \%$ & $27.5 \%$ \\
B & AT584 & $30 \%$ & $10 \%$ & $30.1 \%$ \\
B & AT598 & $40 \%$ & $5 \%$ & $39.1 \%$ \\
A & $15 \%$ & $15 \%$ & $33.7 \%$ \\
C & AT602 & $10 \%$ & $5-10 \%$ & $37.1 \%$ \\
D & AT623 & $50 \%$ & $>1 \%$ & $46.4 \%$ \\
D & AT628 & $5 \%$ & $5 \%$ & $43.3 \%$ \\
D & AT629 & $20 \%$ & $2 \%$ & $46.7 \%$ \\
D & AT630 & $30 \%$ & $5 \%$ & $49.2 \%$ \\
D & AT633 & $20 \%$ & $5 \%$ & $45.8 \%$ \\
\hline
\end{tabular}

the early CST pottery of Assemblage D and the slightly later MST pottery of Assemblage B. Table 3 shows the calcite and mineral content and the apparent porosity of all the sherds with calcareous temper identified in thin section. The single calcareous sherd from Assemblage $\mathrm{C}$ is indistinguishable from those in Assemblage B.

The water-absorption tests show that the CST pottery of Assemblage D has a consistently high porosity, as high as 52.1 percent in one case. The tendency of these sherds to disintegrate easily parallels Moore's experience with her early CST pottery from Tarague. She found that sherds disintegrated during washing in the laboratory, and attributed this to poor firing (1983:78). The porosity values of Assemblages $\mathrm{A}, \mathrm{B}$ and $\mathrm{C}$ range widely, but have almost identical ranges and means (see Appendix 1). In this respect, they form a group apart from the early CST pottery of Assemblage D.

It is not surprising there should be a difference between the two assemblages at Mochong in which calcareous temper is present. Although both assemblages can be attributed to the Intermediate Pre-Latte period on the basis of radiocarbon dates, they are stratigraphically separated within this period. The difference appears to be one of several technological changes in the course of the Marianas pottery tradition.

The Mochong results highlight the complexity of the Marianas pottery sequence, both between islands and within individual islands and even individual sites. Dickinson et al. (2001:838, Table II) analysed eight sherds from an earlier excavation at Mochong by Takayama and Intoh (1976) attributed to the Early Pre-Latte, Intermediate Pre-Latte and Latte periods, and identified three as VST and five as MST. There is no mention of quartz, although the present study found quartz in all Mochong sherds examined. Dickinson et al. (ibid) do report VQT and CQT sherds from Latte-period sites on the east coast of Rota.

Dickinson et al. (2001) provide guidelines for attributing temper sands in some sherds to either Saipan or Guam. Using their results, it could be argued that Assemblage B pottery at Mochong was imported from Saipan. The other assemblages, however, are not so easily attributed, as some sherds contain both quartz in significant amounts (Saipan) and olivine or ferromagnesians (Guam). This raises the possibility that there are, or were, on Mochong clays suitable for pottery manufacture without temper addition and/or sands suitable for temper. Dickinson $e t$ al. point to the need for further research on temper, which this study strongly endorses.

The differential thermal analysis indicated a clear difference between the early $(\mathrm{B}$ and $\mathrm{D})$ and later $(\mathrm{A}$ and $\mathrm{C}$ ) assemblages. The earlier pottery was fired between $600 \mathrm{C}$ and $800 \mathrm{C}$, probably in 
Table 4. Changes through time in Mochong pottery.

\begin{tabular}{llllll}
\hline & & & \multicolumn{3}{l}{ Porosity Firing } \\
\hline Assemblage & Period & Calcite & Quartz & Mean & Temperature \\
\hline A & Latte & absent & low & $36.7 \pm 0.7$ & higher \\
C & Latte & rare & low-medium & $37.0 \pm 1.1$ & higher \\
B & IPL & present & high & $36.0 \pm 1.4$ & lower \\
D & IPL & present & low-high & $45.3 \pm 0.9$ & lower \\
\hline
\end{tabular}

$\mathrm{IPL}=$ Intermediate Pre-Latte.

the lower part of this range, perhaps $650-700 \mathrm{C}$. The later pottery was probably fired at around 900C. Elsewhere in the Pacific, technological aspects of Lapita pottery, including firing, have recently been reviewed by Ambrose (1997:529-530). Low firing temperatures are common in early Pacific pottery (e.g. Intoh 1982:135; Clough 1992:189). Rye (1976) documented the problems that calcareous sand tempers can produce in firing. In the Mochong pottery, the early assemblages, which incorporate calcareous sand temper, were low-fired, while the later assemblages were fired at higher temperatures. It is notable, however, that the single sherd with calcite from the later Assemblage $\mathrm{C}$ also appears to have been fired at a higher temperature.

\section{Conclusions}

Several changes took place in the technology of the pottery used by the people who lived at Mochong. These are summarised in Table 4.

The earliest pottery studied was highly porous; the three subsequent assemblages had lower porosity. Both the earlier assemblages consistently contained deliberately added calcareous sand temper and both were low-fired. In the two later assemblages, most pots were fired at a higher temperature and calcareous temper was present rarely and in small amounts. The two end points of this sequence are the CST and the VST pottery types. On the evidence available for this study, the earlier MST pottery (Assemblage B) is a distinct entity, intermediate between CST and VST. However, the later MST pottery (Assemblage A) is essentially the same as the contemporary VST pottery.

All sherds analysed contain quartz, but the amounts are consistently high only in Assemblage B. This may reflect a specific source for this assemblage. The minerals in the Mochong sherds and the probability that they were, for the most part, present in the clay, rather than deliberately added, suggest that at least some of the Mochong pottery was made on the island, rather than imported from Saipan and Guam.

This study did not include any of the very early pottery known in the Marianas. Even so, the Mochong sequence covers a period of some 2000 years, during which there were significant changes and improvements in pottery technology. The earlier potters coped with the problem of thermal shock by adding significant amounts of calcareous sand temper to the paste and firing at a low temperature. Later potters leaned how to fire their pots successfully at a higher temperature, producing a more durable ware. An important challenge for future research is to see how these changes in technology correlate with the changes in vessel form and possible changes in vessel function discussed by Moore and Hunter-Anderson (1999). There is much still to be learned about how pottery was made, distributed, and used during 3000 years of prehistory in the Mariana Islands. 


\section{References}

Ambrose, W.R. 1997. Contradictions in Lapita pottery, a composite clone. Antiquity 71:525-538.

Anderson, A.J. 1987. Supertramp science: some thoughts on archaeometry and archaeology in Oceania. In W.R. Ambrose and J.M.J. Mummery (eds), Archaeometry: Further Australasian studies, pp. 3-18. Research School of Pacific Studies, Australian National University, Canberra.

Clough, R. 1992. Firing temperatures and the analysis of Oceanic ceramics: a study of Lapita ceramics from Reef/Santa Cruz, Solomon Islands. In J.-C. Galipaud (ed), Poterie Lapita et Peuplement, pp. 177-92. Nouméa: ORSTOM.

Dickinson, W.R. 2006. Temper Sands in Prehistoric Oceanian Pottery: Geotectonics, Sedimentology, Petrography, Provenance. Geological Society of America Special Paper 406.

Dickinson, W.R., B.M. Butler, D.R. Moore and M. Swift 2001. Geologic sources and geographic distribution of sand tempers in prehistoric potsherds from the Mariana Islands. Geoarchaeology $16(8): 827-854$.

Geary, R.C. 1947. Testing for normality. Biometrika 34:209.

Geary, R.C. and E.S. Pearson 1938. Tests of Normality. London: Biometrika Office, University College.

Graves, M.W., T.L. Hunt and D. Moore 1990. Ceramic production in the Mariana Islands: explaining change and diversity in prehistoric interaction and exchange. Asian Perspectives 29:211-233.

Intoh, M. 1982. The Physical Analysis of Pacific Pottery. Unpublished MA thesis, Anthropology Department, University of Otago.

Intoh, M. and B.F. Leach 1985. Archaeological Investigations in the Yap Islands, Micronesia. British Archaeological Reports S277.

Kurashina, H. and R.N. Clayshulte 1983. Site Formation Processes and Cultural Sequence at Tarague, Guam. Tarague Archaeology Special Paper 1. Micronesian Area Research Center, Guam.

Leach, F., M. Fleming, J. Davidson, G. Ward and J. Craib 1988. Prehistoric fishing at Mochong, Rota, Mariana Islands. Man and Culture in Oceania 4:31-62.

Leidemann, H. 1980. Intrasite Variation at Ypao Beach, Guam: a Preliminary Assessment. Unpublished MA thesis, Behavioral Sciences, University of Guam.

Moore, D. 1983. Measuring Change in Marianas Pottery: the Sequence of Pottery Production at Tarague, Guam. Unpublished MA thesis, Behavioral Sciences, University of Guam.

Moore, D.R. and R.L. Hunter-Anderson 1999. Pots and pans in the Intermediate Pre-Latte (2500-1600 bp) Mariana Islands, Micronesia. In J.-C. Galipaud and I. Lilley (eds), Le Pacifique de 5000 à 2000 avant le Présent: Supplements à l'Histoire d'une Colonisation, pp. 487-503.

Paris: Institut de Recherche pour le Développement.

Rao, C.R. 1952. Advanced Statistical Methods in Biometric Research. London: John Wiley.

Ray, E. 1981. The Material Culture of Prehistoric Tarague Beach, Guam. Unpublished MA thesis, Anthropology Department, Arizona State University, Tempe.

Rye, O.S. 1976. Keeping your temper under control: materials and manufacture of Papuan pottery. Archaeology and Physical Anthropology in Oceania 11(2):105-137.

Reinman, F. 1977. An Archaeological Survey and Preliminary Test Excavations on the Island of Guam, Mariana Islands, 1965-1966. Miscellaneous Publication 1, Micronesian Area Research Centre, University of Guam.

Sant, M.B. and N. Lebetski 1988. Ceramics. In B.M. Butler (ed), Archaeological Investigations on the North Coast of Rota, Mariana Islands, pp. 179-253. Southern Illinois University at Carbondale Center for Archaeological Investigations Occasional Paper 8. Carbondale.

Spoehr, A. 1957. Marianas Prehistory: Archaeological Survey and Excavations on Saipan, Tinian and Rota. Fieldiana: Anthropology 48. Chicago: Field Museum of Natural History.

Takayama, J. and M. Intoh 1976. Archaeological Excavation of Latte Site (M-13), Rota, in the Marianas. Reports of Pacific Archaeological Survey IV, Tokai University.

Tite, M.S. 1972. Methods of Physical Examination in Archaeology. London: Seminar Press.

Ward, G.K. and J.L. Craib 1983. Mochong Archaeological Research 1983. Report to CNMI Historic Preservation Office, Saipan. 


\section{Appendix 1}

\section{Results of water-absorption tests}

\section{Assemblage A: MST, Spits 3 and 4}

Sherd AT566 disintegrated during analysis. The results for sherd AT560 are possibly suspect, as the final dry weight was 7\% different from the first determination.

\begin{tabular}{|c|c|c|c|c|}
\hline ACC & WA & AP & BD & SG \\
\hline AT553 & 24.20 & 38.87 & 1.61 & 2.63 \\
\hline AT554* & 19.63 & 34.02 & 1.73 & 2.63 \\
\hline AT555 & 24.05 & 37.08 & 1.54 & 2.45 \\
\hline AT556* & 20.81 & 33.56 & 1.61 & 2.43 \\
\hline AT557* & 21.12 & 34.86 & 1.65 & 2.53 \\
\hline AT558 & 21.31 & 35.23 & 1.65 & 2.55 \\
\hline AT559* & 22.13 & 35.52 & 1.60 & 2.49 \\
\hline AT560 & 19.66 & 33.91 & 1.73 & 2.61 \\
\hline AT561 & 25.57 & 39.30 & 1.54 & 2.53 \\
\hline AT562 & 16.33 & 28.85 & 1.77 & 2.48 \\
\hline AT563 & 19.37 & 32.68 & 1.69 & 2.51 \\
\hline AT564 & 24.84 & 38.48 & 1.55 & 2.52 \\
\hline AT565 & 20.61 & 34.45 & 1.67 & 2.55 \\
\hline AT567 & 23.36 & 36.76 & 1.57 & 2.49 \\
\hline AT568 & 25.07 & 38.80 & 1.55 & 2.53 \\
\hline AT569 & 26.86 & 40.61 & 1.51 & 2.55 \\
\hline AT570 & 21.52 & 34.23 & 1.59 & 2.42 \\
\hline AT571 & 24.64 & 37.21 & 1.51 & 2.40 \\
\hline AT572 & 25.97 & 40.48 & 1.56 & 2.62 \\
\hline AT573 & 23.42 & 37.06 & 1.58 & 2.51 \\
\hline AT574 & 33.68 & 47.34 & 1.41 & 2.67 \\
\hline AT575 & 24.81 & 39.11 & 1.58 & 2.59 \\
\hline AT576 & 23.24 & 35.88 & 1.54 & 2.41 \\
\hline AT577 & 22.85 & 37.24 & 1.63 & 2.60 \\
\hline \multicolumn{5}{|c|}{ Disperson statistics } \\
\hline Mean & $23.13 \pm .69$ & $36.73 \pm .72$ & $1.60 \pm .02$ & $2.53 \pm .02$ \\
\hline SD & $3.37 \pm .49$ & $3.55 \pm .51$ & $0.08 \pm .01$ & $0.07 \pm .01$ \\
\hline G1/W1 & $0.92 / 2.17$ & $0.69 / 1.87$ & $0.09 / 0.69$ & $-0.02 / 0.33$ \\
\hline G2/W2 & $5.47 / 3.67$ & $5.04 / 3.10$ & $3.10 / 0.46$ & $2.25 / 0.69$ \\
\hline
\end{tabular}

* indicates sherd examined in thin section.

Final sample size $=24$. 
Assemblage B: MST, Spits 7 and 8

Sherd AT580 disintegrated during analysis. The results for sherd AT599 are suspect, as the final dry weight was $21 \%$ different from the first determination, showing that some of the sherd disintegrated during analysis.

\begin{tabular}{|c|c|c|c|c|}
\hline ACC & WA & AP & BD & SG \\
\hline AT578 & 22.24 & 34.67 & 1.56 & 2.39 \\
\hline AT579 & 22.54 & 35.52 & 1.58 & 2.44 \\
\hline AT581* & 16.36 & 27.02 & 1.65 & 2.26 \\
\hline AT582 & 32.54 & 44.37 & 1.36 & 2.45 \\
\hline AT583* & 15.60 & 27.50 & 1.76 & 2.43 \\
\hline AT584* & 17.51 & 30.13 & 1.72 & 2.46 \\
\hline AT585 & 19.01 & 31.72 & 1.67 & 2.44 \\
\hline AT586 & 29.62 & 43.02 & 1.45 & 2.55 \\
\hline AT587 & 29.24 & 41.97 & 1.44 & 2.47 \\
\hline AT588 & 35.62 & 47.77 & 1.34 & 2.57 \\
\hline AT589 & 14.41 & 25.35 & 1.76 & 2.36 \\
\hline AT590 & 34.72 & 46.78 & 1.35 & 2.53 \\
\hline AT591 & 15.11 & 26.95 & 1.78 & 2.44 \\
\hline AT592 & 20.66 & 32.12 & 1.55 & 2.29 \\
\hline AT593 & 29.48 & 42.59 & 1.45 & 2.52 \\
\hline AT594 & 29.64 & 42.74 & 1.44 & 2.52 \\
\hline AT595 & 21.94 & 35.08 & 1.60 & 2.46 \\
\hline AT596 & 22.58 & 34.24 & 1.52 & 2.31 \\
\hline AT597 & 20.43 & 33.80 & 1.65 & 2.50 \\
\hline AT598* & 26.12 & 39.08 & 1.50 & 2.46 \\
\hline AT599 & 27.30 & 43.34 & 1.59 & 2.80 \\
\hline AT600 & 19.45 & 30.31 & 1.56 & 2.24 \\
\hline AT601 & 22.08 & 34.43 & 1.56 & 2.38 \\
\hline AT602* & 21.13 & 33.73 & 1.60 & 2.41 \\
\hline \multicolumn{5}{|c|}{ Disperson statistics } \\
\hline Mean & $23.55 \pm 1.27$ & $36.01 \pm 1.37$ & $1.56 \pm .03$ & $2.44 \pm .02$ \\
\hline SD & $6.22 \pm .90$ & $6.69 \pm .97$ & $0.13 \pm .02$ & $0.12 \pm .02$ \\
\hline G1/W1 & $0.38 / 1.40$ & $0.17 / 0.94$ & $0.01 / 0.27$ & $0.78 / 2.00$ \\
\hline G2/W2 & $2.11 / 0.88$ & $1.87 / 1.21$ & $2.19 / 0.78$ & $4.78 / 2.74$ \\
\hline
\end{tabular}

* indicates sherds examined in thin section.

Final sample size $=24$.

\section{Assemblage C: VST, Spits 3 and 4}

One of the original sample of 25 sherds was too small for analysis.

\begin{tabular}{lllll}
\hline ACC & WA & AP & BD & SG \\
\hline AT603 & 25.18 & 39.43 & 1.57 & 2.59 \\
AT604 & 23.39 & 38.06 & 1.63 & 2.63 \\
AT605* & 26.33 & 40.86 & 1.55 & 2.62 \\
AT606 & 13.87 & 25.55 & 1.84 & 2.48 \\
AT607 & 13.31 & 24.66 & 1.85 & 2.46 \\
AT608 & 21.65 & 35.62 & 1.64 & 2.55 \\
\hline
\end{tabular}




\begin{tabular}{|c|c|c|c|c|}
\hline $\mathrm{ACC}$ & WA & AP & $B D$ & SG \\
\hline AT609 & 16.70 & 29.76 & 1.78 & 2.54 \\
\hline AT610 & 21.20 & 33.89 & 1.60 & 2.42 \\
\hline AT611 & 21.85 & 36.10 & 1.65 & 2.59 \\
\hline AT612 & 22.45 & 36.96 & 1.65 & 2.61 \\
\hline AT613 & 13.92 & 25.67 & 1.84 & 2.48 \\
\hline AT614 & 29.24 & 43.41 & 1.48 & 2.62 \\
\hline AT615 & 30.89 & 44.32 & 1.43 & 2.58 \\
\hline AT616 & 23.91 & 38.45 & 1.61 & 2.61 \\
\hline AT617 & 26.08 & 40.98 & 1.57 & 2.66 \\
\hline AT618 & 27.02 & 41.59 & 1.54 & 2.63 \\
\hline AT619* & 24.96 & 39.65 & 1.59 & 2.63 \\
\hline AT620* & 27.30 & 41.72 & 1.53 & 2.62 \\
\hline AT621 & 23.53 & 36.99 & 1.57 & 2.49 \\
\hline AT622 & 23.12 & 37.44 & 1.62 & 2.59 \\
\hline AT623* & 22.74 & 37.08 & 1.63 & 2.59 \\
\hline AT624* & 26.07 & 41.00 & 1.57 & 2.67 \\
\hline AT625 & 26.21 & 40.28 & 1.54 & 2.57 \\
\hline AT626 & 23.35 & 38.52 & 1.65 & 2.68 \\
\hline \multicolumn{5}{|c|}{ Disperson statistics } \\
\hline Mean & $23.10 \pm 0.94$ & $37.00 \pm 1.12$ & $1.62 \pm 0.02$ & $2.58 \pm 0.01$ \\
\hline SD & $4.63 \pm 0.67$ & $5.48 \pm 0.79$ & $0.11 \pm 0.02$ & $0.07 \pm 0.01$ \\
\hline G1/W1 & $-0.80 / 2.03$ & $-1.11 / 2.39$ & $0.87 / 2.11$ & $-0.74 / 1.95$ \\
\hline G2/W2 & $3.10 / 0.46$ & $3.33 / 0.77$ & $3.18 / 0.57$ & $1.36 / 1.89$ \\
\hline
\end{tabular}

Final sample size $=24$.

Assemblage D: CST, Spits 9, 10 and 11

Sherds AT631, AT646, AT649, and AT650 disintegrated during analysis. The results for sherd AT629 are possibly suspect, as the final dry weight was $6.5 \%$ different from the first determination. One of the original sample of 25 sherds was too small for analysis.

\begin{tabular}{lllll}
\hline ACC & WA & AP & BD & SG \\
\hline AT627 & 33.68 & 48.06 & 1.43 & 2.75 \\
AT628* & 33.14 & 46.44 & 1.40 & 2.62 \\
AT629* & 29.66 & 43.25 & 1.46 & 2.57 \\
AT630* & 32.07 & 46.72 & 1.46 & 2.73 \\
AT632 & 25.21 & 39.77 & 1.58 & 2.62 \\
AT633* & 35.44 & 49.16 & 1.39 & 2.73 \\
AT634 & 34.28 & 48.59 & 1.42 & 2.76 \\
AT635 & 47.10 & 1.48 & 2.80 \\
AT636 & 31.83 & 36.73 & 1.61 & 2.55 \\
AT637 & 22.77 & 49.38 & 1.38 & 2.72 \\
AT638 & 35.90 & 44.66 & 1.42 & 2.56 \\
AT639 & 31.53 & 42.41 & 1.53 & 2.65 \\
AT640 & 27.81 & 48.42 & 1.39 & 2.70 \\
AT641 & 34.82 & 46.21 & 1.41 & 2.63 \\
\hline
\end{tabular}




\begin{tabular}{lllll}
\hline ACC & WA & AP & BD & SG \\
\hline AT642 & 27.73 & 42.85 & 1.54 & 2.70 \\
AT643* & 30.92 & 45.82 & 1.48 & 2.74 \\
AT644 & 38.18 & 51.21 & 1.34 & 2.75 \\
AT645 & 33.58 & 48.81 & 1.45 & 2.84 \\
AT647 & 29.67 & 43.46 & 1.46 & 2.59 \\
AT648 & 22.55 & 35.90 & 1.59 & 2.48 \\
\hline Disperson statistics & & & & \\
\hline Mean & $31.17 \pm 0.95$ & $45.25 \pm 0.93$ & $1.46 \pm 0.02$ & $2.67 \pm 0.02$ \\
SD & $4.23 \pm 0.67$ & $4.16 \pm 0.66$ & $0.08 \pm 0.01$ & $0.09 \pm 0.01$ \\
G1/W1 & $-0.63 / 1.68$ & $-0.87 / 1.97$ & $0.58 / 1.60$ & $-0.24 / 1.04$ \\
G2/W2 & $2.70 / 0.01$ & $2.98 / 0.35$ & $2.47 / 0.32$ & $2.11 / 0.79$ \\
\hline
\end{tabular}

Final sample size $=20$.

\section{Appendix 2 \\ Descriptions of thin sections}

\section{Assemblage A: MST, Spits 3 and 4}

AT554. Mineral content 20\%, moderately rounded to subangular grains, up to $1 \mathrm{~mm}$, $60 \%$ andesine-labradorite, somewhat weathered, $10 \%$ quartz and 10\% rock fragments (quartzo-feldspathic). Matrix brownish yellow (10YR 6/8) with pale reddish orange (2.5YR 7/4) inclusions, compact, few voids, shows flow structure.

AT556. Mineral content 1-2\%, angular grains, up to $0.4 \mathrm{~mm}, 70 \%$ andesine, $20 \%$ magnetite, $5 \%$ quartz and 5\% augite. Matrix pinkish grey (7.5YR 7/3), mottled orange (2.5YR 7/8) and light reddish brown (2.5YR 6/4), shows vague flow structure and about $30 \%$ voids. Some voids may have been occupied by mineral grains, some reddish nodules may represent weathered ferromagnesians.

AT557. Mineral content 5\%, small semiangular grains, up to $0.5 \mathrm{~mm}, 60 \%$ andesine, $20 \%$ magnetite, $10 \%$ augite and $10 \%$ quartz. Matrix brownish yellow (10YR 6/8) with red $(7.5 \mathrm{R}$ 4/8) blotches, shows flow structure, many elongated voids and some rounded vesicles filled with clay which may represent weathered ferromagnesians.

AT559. Mineral content 2\%, small angular grains, up to $0.15 \mathrm{~mm}$, composition of mineral fraction 50\% augite, 25\% labradorite and 25\% quartz. Matrix brownish yellow (10YR 7/3) with some pink (7.5YR 7/4) and reddish yellow (7.5YR 6/6) nodules, fine silty texture, irregularly fractured.

\section{Assemblage B: MST, Spits 7 and 8}

AT581. Mineral content $10 \%$, angular fragments up to $0.75 \mathrm{~mm}, 90 \%$ quartz, and $10 \%$ magnetite, no ferromagnesians or feldspars seen. Calcite 10\%, stained rounded fragments without shell structure, $0.4 \mathrm{~mm}$. Matrix reddish yellow (5YR 7/8) and black (5YR 2/1), banded, many lenticular cracks parallel to axis of sherd.

AT583. Mineral content $1 \%$, angular fragments, up to $0.75 \mathrm{~mm}, 90 \%$ quartz, $10 \%$ magnetite. Calcite 20\%, shell fragments, $0.5 \mathrm{~mm}$. Matrix yellowish red (5YR 5/6) with few light red (10R 6/8) mottles, compact, few lenticular voids.

AT584. Mineral content 10\%, angular grains, some up to $1 \mathrm{~mm}, 90 \%$ quartz, $10 \%$ magnetite. 
Calcite 30\%, as rounded shell fragments, $0.5 \mathrm{~mm}$. Matrix strong brown (7.5YR 4/8), many lenticular cracks parallel to surface of sherd.

AT598. Mineral content 5\%, up to $1 \mathrm{~mm}$, 90\% quartz, $10 \%$ magnetite. Calcite $40 \%$, rounded shell fragments, up to $1 \mathrm{~mm}$. Matrix banded red (10R 5/8) and dusky red (10R 3/3).

AT602. Mineral content 15\%, up to $1 \mathrm{~mm}, 90 \%$ quartz, 5\% andesine, 5\% magnetite. Calcite $15 \%$, shell fragments, up to $1 \mathrm{~mm}$. Matrix red (10R 4/6) to light red (10R 6/8), banded with globules of red clay present, many lenticular cracks parallel to axis of sherd.

\section{Assemblage C: VST, Spits 3 and 4}

AT605. Mineral content 10\%, 90\% andesine, 5\% quartz and 5\% augite. Matrix orange (2.5YR 7/8) with red (10R 5/8) mottles, compact, many fine lenticular voids.

AT619. Mineral content $15 \%$, small angular grains, $0.5 \mathrm{~mm}, 50 \%$ labradorite, $25 \%$ rock fragments, $10 \%$ augite, $5 \%$ quartz. Matrix reddish yellow (5YR 7/8) to red (10R 5/8), pleochroic due to oriented clay particles, few large cracks parallel to axis of sherd.

AT620. Mineral content 5\%, fragments up to $0.5 \mathrm{~mm}, 50 \%$ quartz, $50 \%$ augite. Matrix reddish yellow (5YR 7/8) with strong brown (7.5YR 5/8) to reddish yellow (7.5YR 6/8) mottles, fine globular structure, broken into small fragments with many voids.

AT623. Mineral content $10 \%$, angular, $0.25 \mathrm{~mm}, 80 \%$ quartz and $20 \%$ magnetite. Calcite 5-10\%, rounded shell fragments, $0.5 \mathrm{~mm}$. Matrix reddish brown (5YR 5/4), compact, about $5-10 \%$ globular clay aggregates which may have been weathered feldspars or ferromagnesians, compact, thin lenticular voids parallel to axis of sherd.

AT624. Mineral content 5\%, fragments $0.3 \mathrm{~mm}, 70 \%$ andesine, $15 \%$ quartz and $15 \%$ augite. Matrix red (10R 5/8), birefringent and shows flow structure of clay aggregates, some globules may be altered feldspars or ferromagnesians, compact, many fine lenticular cracks.

\section{Assemblage D: CST, Spits 9, 10 and 11}

AT628. Mineral content $<1 \%$, quartz only, $0.2 \mathrm{~mm}$. Calcite $50 \%$, shell fragments, $0.3 \mathrm{~mm}$. Matrix light red (10R 6/8), clay shows flow structures around shell fragments, many cracks perpendicular and parallel to axis.

AT629. Mineral content 5\%, fragments $0.2 \mathrm{~mm}$, 40\% labradorite, $20 \%$ quartz, $20 \%$ magnetite, $10 \%$ olivine and $10 \%$ augite. Calcite $5 \%$, rounded grains, very strongly weathered, shell structure not visible, $0.5 \mathrm{~mm}$. Matrix reddish yellow (5YR 7/8) and red (10R 5/8), pleochroic, no preferred orientation shown, some large cracks parallel to axis of sherd.

AT630. Mineral content 2\%, fragments $0.25 \mathrm{~mm}, 40 \%$ quartz, $40 \%$ oligoclase, $15 \%$ magnetite and 5\% horneblende. Calcite 20\%, rounded shell fragments, $0.3 \mathrm{~mm}$. Matrix red (10R 5/8), shows pleochroic flow structures, many cracks parallel to axis of sherd and many large voids which may be due to plucking of grains during grinding.

AT633. Mineral content 5\%, fragments $0.2 \mathrm{~mm}, 40 \%$ quartz, $40 \%$ andesine, $15 \%$ magnetite and 5\% horneblende. Calcite 30\%, shell fragments, $1 \mathrm{~mm}$. Matrix yellowish red (5YR 4/6), birefringent but does not show prominent flow structures, many fine cracks parallel to axis of sherd.

AT643. Mineral content 5\%, angular fragments, up to $0.5 \mathrm{~mm}, 95 \%$ quartz, $5 \%$ magnetite. Calcite 20\%, rounded fragments without obvious shell structure, $0.5 \mathrm{~mm}$. Matrix mottled light red (10R 6/8) and reddish brown (5YR 4/4), many fine cracks with no apparent preferred orientation. 